\title{
AVALIAÇÃO TEMPORAL DO CRESCIMENTO DA MANCHA URBANA NO SETOR OESTE DA RESERVA DA BIOSFERA DO CINTURÃO VERDE (RBCV)
}

\author{
Leite, J.R. ${ }^{12}$; Pellegrino, P. R. M. ${ }^{3}$, Modesto, A. A. L. ${ }^{4}$
}

\section{RESUMO}

O presente artigo refere-se a um estudo onde foi realizada uma avaliação temporal do crescimento urbano, por classificação supervisionada de imagens do satélite Landsat 5 em quatro momentos entre 1975 e 2010, no setor Oeste da RBCV. Buscouse relacionar a expansão urbana com a supressão da vegetação ocorrida no período. Foram produzidos quatro mapas sobre o uso do solo nas quatro datas avaliadas, além de gráficos e tabelas para a discussão dos resultados. Dois mapas resultantes da avaliação, sobre as Áreas de Maior Supressão da Vegetação e Concentração do Crescimento Urbano foram elaborados. O primeiro indicou as áreas em que, em cada momento avaliado, tiveram fragmentos de vegetação de porte florestal suprimidos. O segundo trouxe a interpretação da morfologia de crescimento urbano que se caracteriza por assumir uma forma radial, seguindo os eixos das principais rodovias ampliando as suas possibilidades de conexões e de propagação de seus impactos até áreas mais periféricas da Metrópole.

Palavras-chave: Classificação supervisionada; Máxima verossimilhança; Análise temporal da paisagem; Infraestrutura verde urbana; Planejamento ecológico da paisagem.

\section{TEMPORAL ASSESSMENT OF URBAN GROWTH AT THE SÃO PAULO GREEN BELT BIOSPHERE RESERVE, WEST SECTOR}

\begin{abstract}
This abstract refers to a study in which was made an evaluation of temporal assessment urban growth by supervised classification of Landsat 5 satellite images between 1975 and 2010, which sought to relate the same with the removal of vegetation in the period. Four land use maps were produced in the four dates evaluated, as well as graphs and tables for the results discussion. Two maps from the evaluation on the Greater Suppression of Vegetation and Concentration of Urban Growth Areas were of great importance to discussions of the results. The first one indicated the areas where, in which evaluated date, there were forest fragments removed. The second one brought up the interpretation of the morphology of urban growth that is characterized by assuming a radial form, following the axis of the main highways extending the possibilities of connections and spread its impacts to the more peripheral areas of the metropolis.
\end{abstract}

Keywords: Supervised classification; Maximum likelihood; Landscape temporal analysis; Green infrastructure; Landscape ecological planning.

\footnotetext{
${ }^{1}$ Julia Rodrigues Leite. Bióloga. Doutora e Mestre da Faculdade de Arquitetura e Urbanismo, Universidade de São Paulo (FAU-USP). Depto de Projeto. Área de Concentração Paisagem e Ambiente. LABVerde. São Paulo, SP. juliardl@gmail.com

${ }^{2}$ Data recebimento: 29/09/2011 - Data de publicação: 15/12/2012

${ }^{3}$ Paulo Renato Mesquita Pellegrino. Arquiteto e Urbanista. Professor Doutor da Faculdade de Arquitetura e Urbanismo, Universidade de São Paulo (FAU-USP). Depto de Projeto. Área de Concentração Paisagem e Ambiente. LABVerde. São Paulo, SP. prmpelle@gmail.com

${ }^{4}$ Adão Aparecido Lanzieri Modesto. Geógrafo. Faculdade de Filosofia, Letras e Ciências Humanas, Universidade de São Paulo(FFLCHUSP). São Paulo, SP. adaomodesto@ig.com.br.
} 


\section{INTRODUÇÃO}

A constante destruição dos ecossistemas naturais em decorrência de atividades urbanas, diminuindo e isolando os habitats disponíveis, fazem com que os processos de fragmentação de áreas de conservação, prejudiquem a dinâmica ecológica da área estudada e sejam problemas enfrentados por gestores de unidades de conservação e de profissionais envolvidos com planejamento territorial urbano. A fragmentação e a conectividade são dois conceitos amplamente discutidos em estudos e pesquisas científicas em ecologia da paisagem e de fundamental importância para o planejamento ecológico da paisagem. São conceitos relacionados, pois, a partir da fragmentação de habitats e de ecossistemas, pode vir a ocorrer a perda de conectividade entre eles, comprometendo e inviabilizando, ao longo do tempo, a existência de populações (FAHRIG, 2003). Junto a esses processos, ocorre a própria perda de áreas de habitat e consequente redução no tamanho médio dos fragmentos, aumento do isolamento entre eles e também das áreas de contato entre habitat e não-habitat (efeito de borda ${ }^{5}$ ). Tratase de um processo que resulta em diferentes configurações espaciais dos remanescentes na paisagem, pois o tamanho, formato e a posição dos fragmentos influenciam o estabelecimento de conexões entre os seres vivos.

Importante realçar que a área estudada possui características periurbanas, moldadas por fortes

5 Os efeitos de bordas mais comuns são: elevação da temperatura e luminosidade e redução de umidade (Metzger, 1999). influências da complexa dinâmica metropolitana que atende a diversas funções sociais como habitação; preservação ambiental, mobilidade; transporte; redes de infraestrutura; desenvolvimento econômico.

As áreas de vegetação em locais urbanos são vistas como grandes desafios de manejo para os profissionais preocupados com a biodiversidade, e não apenas como terrenos baldios biologicamente pouco significativos, de pouca importância socioeconômica ou destinados apenas ao lazer (MAGALHAES, 2005; AHERN, 1991). A densidade de ocupação destaca a tensão presente em torno das áreas não ocupadas, os espaços abertos, muitos deles com seus destinos incertos e com ausência de regulamentação. Com isso, acabam sendo afetados profundamente, comprometendo a dinâmica ecológica geral da região e a viabilidade de muitas espécies.

Compreender, por meio da análise temporal, o processo de fragmentação no trecho estudado, entre outros processos, foi de suma importância para o inicio do estudo de uma proposta acadêmica de corredores ecológicos (LEITE, 2012) os quais foram delineados por um minucioso processo de planejamento ecológico relacionado à dissolução de conflitos e otimização dos benefícios dos serviços ambientais existentes nas paisagens (RODRIGUES et al, 2006).

O trecho contém fragmentos florestais e uma condição não completamente urbanizada, pela qual se justifica uma discussão de conservação de elementos naturais, como a vegetação, nascentes, rios, riachos e fauna presentes na área os quais viabilizam e justificam a implementação de 
sistema de corredores ecológicos (HELLMUND, 2006).

Diante da intensa pressão de desenvolvimento que alguns trechos mais urbanizados realizam sobre as áreas ainda não urbanizadas, sejam elas cobertas com florestas, capoeiras, campos, reflorestamento ou até mesmo com solo exposto, considerou-se importante, para avançar numa proposta de implantação de corredores ecológicos, a realização de um estudo temporal para se avaliar o padrão de crescimento urbano ao longo das três ultimas décadas, iniciando na década de 70, pela disponibilidade de imagens de satélite, mas também quando no Brasil, a população urbana superou a rural (MEYER; GROINSTEIN, 2004).

Assim o presente artigo não se propõe a discutir a proposta dos corredores em si, mas apresentar o estudo realizado sobre a dinâmica de ocupação da área estudada em 3 décadas e com esses dados tentar justificar e discutir a necessidade de ações e propostas de conservação no setor de conservação, como a implementação de corredores ecológicos.

Com o intuito de se verificar a intensidade e do crescimento urbano na área estudada buscou-se realizar uma análise temporal do mesmo e consequentemente da supressão da vegetação na área estudada por meio de análises de imagens de satélite em 4 datas: 1975, 1986, 1995 e 2010.

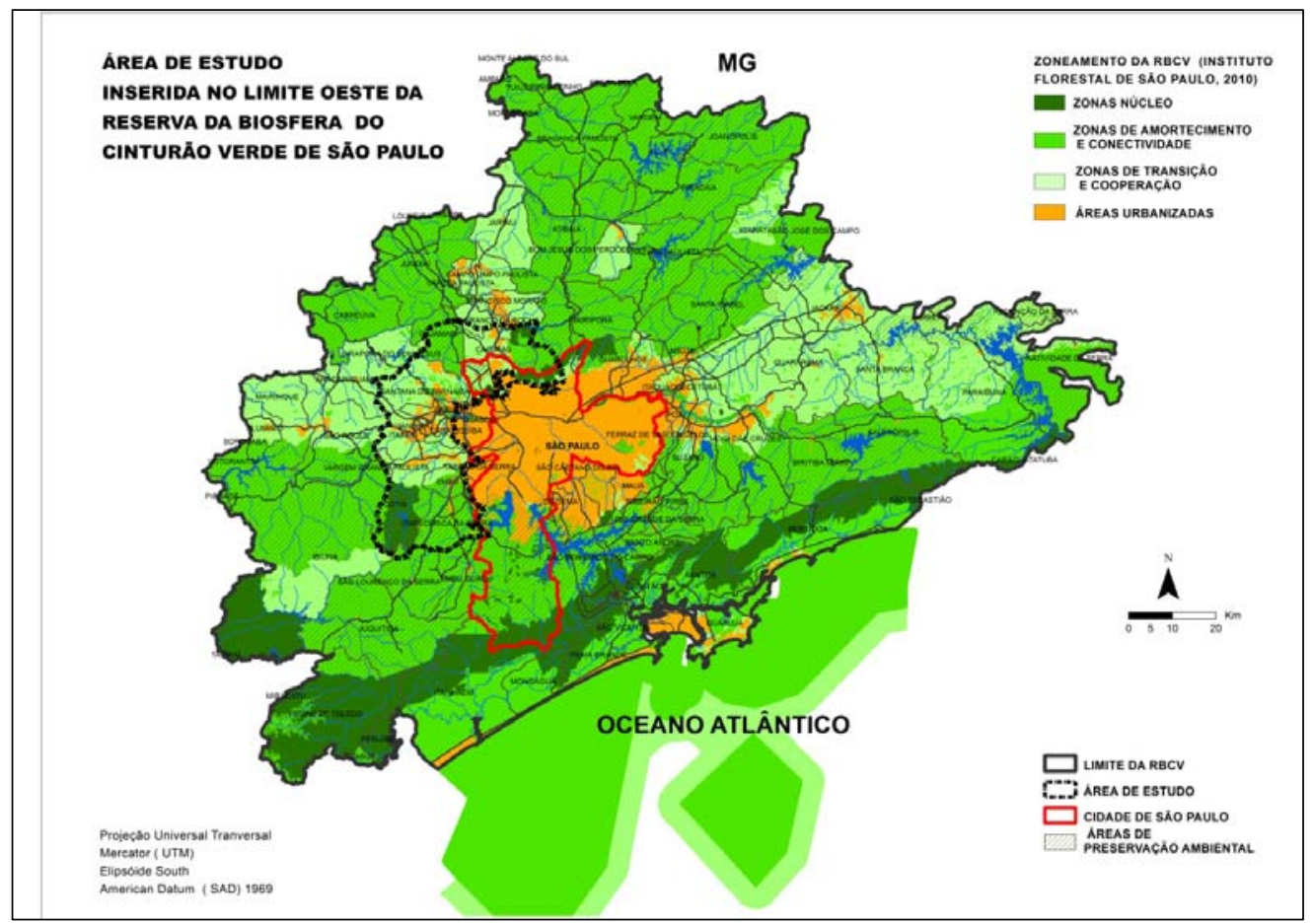

Figura 1 - Localização da área de estudo.

\section{MATERIAIS E MÉTODOS}


A área estudada encontra-se na Região Metropolitana de São Paulo (RMSP), na porção oeste de seu aglomerado urbano principal, está compreendida no retângulo formado pelas coordenadas $47^{\circ} 2^{\prime} 3^{\prime \prime} \mathrm{W}, 23^{\circ} 19^{\prime} 2^{\prime \prime S}$ e 46³6'42"W, 2348'28"S. De acordo com a classificação de Köppen-Geiger a área de estudo é caracterizada pelo clima tropical de altitude, com chuvas no verão e seca no inverno, com a temperatura média do mês mais quente superior a $22^{\circ} \mathrm{C}$. (MIRANDA et al). O tipo vegetacional original predominante, cujos remanescentes recobrem a maior parte da RMSP, são classificados como Floresta Ombrófila Densa (VELOSO 1992; VELOSO et al., 1991; IBGE, 1993). Corresponde à quinta região metropolitana mais populosa do planeta (UNESCO, 2010), com quase 20 milhões de habitantes e ao centro econômico e financeiro brasileiro. O trecho contém características de uma área periurbana, já que se localiza na borda da região metropolitana densamente urbanizada, e guarda ainda áreas pouco povoadas.

O setor estudado inclui parcelas de 17 municípios onde Barueri, Caieiras, Jandira e Santana do Parnaíba possuem todo seu território compreendido em seus limites e Cajamar, Carapicuíba, Cotia, Embu das Artes, Franco da Rocha, Itapecerica da Serra, Itapevi, Mairiporã, Osasco, São Lourenço da Serra, São Paulo, Taboão da Serra e Vargem Grande Paulista contem apenas uma parte incluída na área.

Alguns instrumentos legais federais, estaduais e municipais (APPs, Unidades de Conservação, APAs, Parques Estaduais, Parques Municipais, Área de Proteção aos Mananciais, Zoneamentos de Planos Diretores Municipais) regulam o uso no trecho, entretanto ainda está sujeito a grandes pressões ao desenvolvimento urbano, especialmente pela presença de rodovias e proximidade com centros urbanos como os dos municípios de Barueri, Santana de Parnaíba , Osasco, Caieiras e São Paulo os quais atuam como vetores de crescimento urbana na área.

O trecho estudado também faz parte da Reserva da Biosfera do Cinturão Verde de São Paulo (RBCV), que é administrada pelo Instituto Florestal de São Paulo e possui apoio da United Nations Educational, Scientific and Cultural Organization UNESCO para sua gestão e conservação. De acordo com Lino et al. (2009), o zoneamento para RBCV é formado por três categorias para o planejamento da ocupação e uso do solo e de seus recursos ambientais. As Zonas Núcleo representam áreas significativas de ecossistemas específicos, em sua maioria, compostas por Unidades de Conservação Estaduais, mas estão incluídas na categoria Áreas de Proteção Integrais.

As Zonas de Amortecimento e Conectividade são constituídas pelas áreas subjacentes às zonas núcleo. As Zonas de Transição e Cooperação são constituídas pelas áreas externas às Zonas de Amortecimento e permitem um uso mais intensivo, porém não destrutivo de seus recursos ambientais. Essas áreas correspondem às restantes, com exceção das grandes manchas urbanas e são voltadas para o desenvolvimento sustentável.

A área estudada contém três remanescentes de vegetação florestal, que foram considerados neste estudo como áreas naturais de extrema importância como refúgio de espécies animais e vegetais no contexto regional do trecho selecionado: Parque Estadual da Cantareira, Reserva do Morro Grande e Morro do Boturuna. 
A rodovia mais antiga instalada na área é a rodovia SP 330 - Anhanguera, em 1914 foi construído o seu primeiro trecho e em 1940 o segundo, a mesma atravessa no trecho estudado os municípios de São Paulo, Cajamar e Osasco. A rodovia mais recente que atravessa a área é a SP 211-Rodoanel Mário Covas trecho oeste (2002) e trecho Sul (2010), que atravessam, no trecho estudado os municípios de Itapecerica da Serra, Embu, Taboão da Serra, Carapicuíba, Cotia, Barueri, Santana de Parnaíba, São Paulo, Mairiporã.

A Linha Férrea 8 Metropolitana (CPTM) exerce um papel fundamental para a conformação do tecido urbano da área estudada. Seu traçado é muito antigo é corresponde a antiga Estrada de Ferro Sorocabana, construída em 1870 para o transporte de carga, passando a operar, a partir dos anos 1920 como transporte suburbano e atende ao transporte público intermunicipal. Na área estudada serve aos municípios de Itapevi, Jandira, Barueri e Carapicuíba.

A malha viária principal é composta pela Rodovia dos Bandeirantes - SP 348 (1978), Rodovia Castello Branco - SP 280 (1968), Estrada dos Romeiros - SP 312 (sem data), Rodovia SP-274 (sem data), Rodovia Raposo Tavares-SP 270 (1937) e a Rodovia Regis Bittencourt BR -116(1951).

A data de implantação das rodovias foi um dado que norteou a definição das datas a serem estudadas. Mas foi a disponibilidade de imagens de satélite gratuitas que foi determinante como fator de escolha para a primeira data da avaliação, 1975.

\section{Seleção e obtenção das imagens}

Para a seleção das datas estudadas optou-se pela escolha das imagens disponíveis mais antigas (1975) e mais recentes, à época da realização do trabalho, (2010) e duas datas entre estas (1986 e 1995).

Para realização do uso do solo foram adquiridas imagens de uso livre dos satélites da família Landsat (1, 5 e 7) junto ao INPE (Instituto Nacional de Pesquisas Espaciais). Para tanto foram selecionadas as cenas que recobririam o polígono envolvente da área a ser mapeada.

Foram selecionadas imagens de 4 datas diferentes a saber, 27/05/1975; 19/06/1986; 28/06/1995 3 04/05/2010, de modo a permitir uma amostragem em cada uma das décadas que possuíam imagens disponíveis. Também se buscou concentrar a seleção nos meses com imagens disponíveis para todos os anos.

\section{Escolha do software}

Para correção geométrica e processamento dos dados optou-se pelo programa Ilwis (Integrated Land Water Information System) desenvolvido pelo holandês ITC (Faculty of Geo-Information Science and Eath Observation of the University of Twente) de uso livre (disponível em http://www.itc.nl/ilwis/downloads/ilwis33.asp )

\section{Base cartográfica para auxílio}

Para a correção geométrica das imagens adquiridas foi necessária a obtenção de uma base cartográfica auxiliar para realização do novo georreferenciamento. A base escolhida foi $\mathrm{o}$ sistema viário da Região Metropolitana de São Paulo em formato shapefile publicada pela EMPLASA (2006).

\section{Pré-processamento das imagens}

As imagens de satélite possuem distorções sistemáticas que são resultantes do processo de aquisição e imprecisão dos dados de 
posicionamento da plataforma (D’ÁLGE, 2001). Para corrigi-lo, foi realizado um novo georreferenciamento nas imagens utilizando o software Ilwis a partir da base cartográfica da RMSP, ficando todas as imagens como o mesmo referencial geodésico - projeção UTM (Universal Transversa de Mercartor), Fuso 23., datum SAD 69 (South American Datum).

Para uniformização da unidade mínima cartografável, - pixel - procedimento necessário já que as imagens são multitemporais e apresentam pixels variando entre 30 e 90 metros, as imagens foram re-amostradas, resultando em imagens uniformes com pixels de 30 metros.

Em seguida foi realizado o realce de contraste tendo como base seu histograma, este procedimento visa melhorar a qualidade da imagem, permitindo uma melhor discriminação dos objetos presentes na mesma (INPE, s/d), ou seja, torna mais fácil o reconhecimento de padrões de uso e ocupação do solo.

\section{Classes de uso e ocupação do solo}

Em uma primeira fase a interpretação das imagens orbitais baseou-se nos elementos clássicos da fotointerpretação definidos por padrões específicos (MOREIRA, s/d, VENTURIERI, 2007), são eles:

Cores: variação de acordo com a composição colorida, para este trabalho foi realizada uma composição colorida das imagens para facilitar a identificação dos padrões de uso, na qual a vegetação aparece em tons de verdes, edificações e solo exposto variando em tons de vermelho e água em preto.
Textura: variação da rugosidade da feição, variando do liso ao altamente rugoso.

Tonalidade: considera-se o brilho encontrado na área mapeada, variando do baixo ao muito alto.

Forma: variação geométrica das feições identificadas na imagem, variando do regular ao muito irregular.

Convencionou-se identificar as seguintes classes de uso e ocupação do solo:

- Área edificada: identificada na imagem em tons de vermelho e geralmente com forma geométrica bem formada.

- Solo exposto: variação dos tons do vermelho com ou sem forma geométrica definida e rugosidade lisa.

- Áreas de mata: tons de verde escuro, geralmente sem forma geométrica definida, exceto em caso de parques e com bastante rugosidade. Para o objetivo deste trabalho, eventuais tipos de florestas presentes na área foram agrupados em uma única classe.

- Áreas de reflorestamento: variando em tons de verde claro e geralmente com forma geométrica bem definida - talhões - e com baixa rugosidade.

- Áreas de campo: variação dos tons de verde podendo apresentar ou não forma geométrica bem definida e com rugosidade lisa. Para o objetivo deste trabalho, eventuais tipos de campos presentes na área foram agrupados em uma única classe)

- Corpos d'água: identificada através de corpos negros. 


\section{Classificação supervisionada do uso e ocupação do solo}

Para a elaboração do mapeamento do uso do solo foi adotado o método da classificação supervisionada e o classificador Máxima Verossimilhança, uma das técnicas de classificação mais utilizadas dentro do sensoriamento remoto (SOARES et al, 2011; LUCHIARI, 2001; NOVACK et al, 2007). Ela consiste na criação de amostras que o programa utilizará como suporte para encontrar pixels similares e classificá-los como tal.

Após esses processos deu-se início a classificação supervisionada do uso e ocupação do solo das imagens, o produto resultante deste processo foi submetido a um filtro majoritário de modo a suavizar e dar uma maior homogeneidade ao produto.

\section{Classificação supervisionada}

O método da classificação supervisionada possui limitações decorrentes da automação computacional

\section{RESULTADOS E DISCUSSAO}

Mesmo com todas estas questões a metodologia conseguiu apontar o crescimento da mancha urbana nos últimos 35 anos evidenciando a expansão do processo de adensamento urbano a partir dos vetores do sistema viário.

Dentre os resultados encontrados, destacam-se o mapeamento do Uso do Solo nas quatro datas estudadas: 1975, 1986, 1995 e 2010 e as informações tabulares decorrentes destes produtos. dos processos, que a torna menos precisa que a classificação manual das classes, todavia, apresenta uma ótima relação custo/benefício quando em grandes áreas de estudo.

Outra limitação foi a resolução espectral/espacial das imagens de 1975 (4 bandas e 90m respectivamente) que impossibilitaram a separação das classes mata e reflorestamento para este ano.

\section{Mapa da Concentração de Crescimento Urbano} e da Supressão da Vegetação

Com dados georreferenciados do Uso o Solo provenientes do mapeamento da EMPLASA, (2006), foi montado o mapa de Concentração do Crescimento Urbano indicando o padrão morfológico do crescimento no setor estudado. Já para a elaboração do mapa da Supressão da Vegetação utilizou-se também os polígonos de Mata e Reflorestamento, nos quatro momentos avaliados, produzidos pela classificação supervisionada já descrita. Utilizou-se ferramentas de geoprocessamento com o uso do software Arcgis 9.3 da ESRI® para a produção dos mapas.
Um quadro síntese contendo as quatro imagens interpretadas foi montado para facilitar a interpretação (Figura 2).

A Tabela 1 e os Gráficos 1 e 2 contém as áreas de cada classe de uso encontradas em hectares (ha) e o percentual que esta representa da área total e expressam o índice de crescimento absoluto de cada classe de uso do solo ao longo do tempo. O Gráfico 1 contém a representação das alterações absolutas AVALIAÇÃO TEMPORAL DO CRESCIMENTO DA... 
sofridas em cada classe de uso estudada para cada período. O Gráfico 2 possui barras que representam a soma das áreas de cada classe de uso do solo dentro área total de estudo, nele é possível visualizar o percentual de crescimento absoluto e relacioná-lo com aumento relativo em cada classe e respectivas datas.

Tabela 1 - Análise temporal do uso do solo.

\begin{tabular}{|c|c|c|c|c|c|c|c|c|}
\hline \multirow[b]{2}{*}{ CLASSE } & \multicolumn{2}{|c|}{$1975 *$} & \multicolumn{2}{|l|}{1986} & \multicolumn{2}{|c|}{1995} & \multicolumn{2}{|c|}{2010} \\
\hline & Hectares & $\%$ & Hectares & $\%$ & Hectares & $\%$ & Hectares & $\%$ \\
\hline Água & $1.428,0$ & 1,2 & $1.731,9$ & 1,4 & $1.100,8$ & 0,9 & 833,6 & 0,7 \\
\hline Área urbana & $11.590,2$ & 9,5 & $9.083,1$ & 7,5 & $12.609,5$ & 10,4 & $14.527,1$ & 11,9 \\
\hline $\begin{array}{l}\text { Campo/ } \\
\text { Capoeira }\end{array}$ & $42.680,4$ & 35,1 & $43.538,6$ & 35,8 & $33.051,5$ & 27,2 & $46.674,1$ & 38,4 \\
\hline Mata total & $64.234,8$ & 52,8 & $51.335,3$ & 42,2 & $54.476,1$ & 44,8 & $44.336,8$ & 36,5 \\
\hline Reflorestamento & - & 0,0 & 11.509,1 & 9,5 & 16.743,3 & 13,8 & $10.224,7$ & 8,4 \\
\hline S/ dado total & - & 0,0 & 208,0 & 0,2 & - & 0,0 & 2,3 & 0,0 \\
\hline Solo exposto & $1.697,5$ & 1,4 & $4.225,0$ & 3,5 & $3.649,8$ & 3,0 & $5.032,2$ & 4,1 \\
\hline Total & $121.630,9$ & $100 \%$ & $121.630,9$ & $100 \%$ & $121.630,9$ & $100 \%$ & $121.630,9$ & 100 \\
\hline
\end{tabular}



Gráfico 1 - Análise Temporal das classes de uso do solo. 


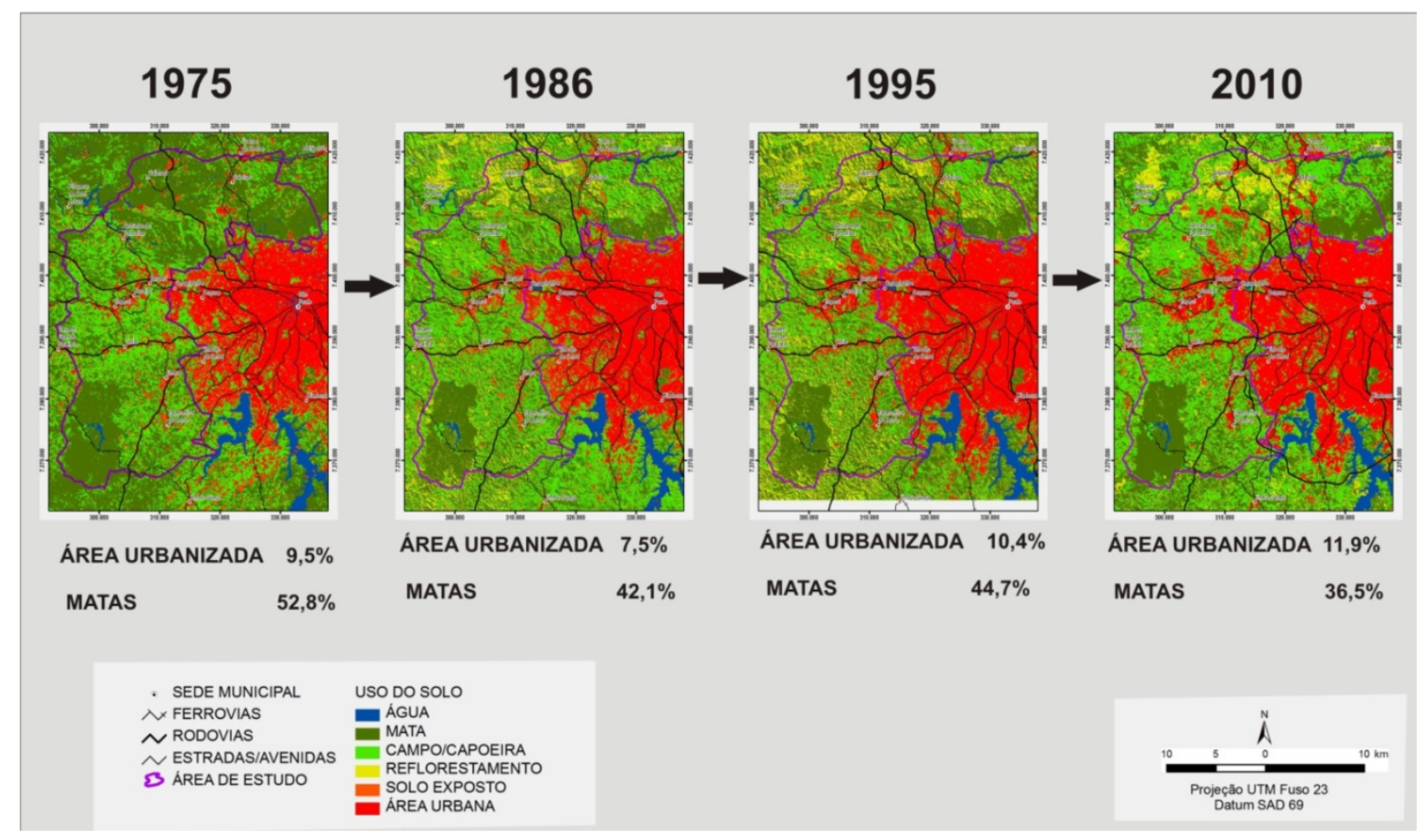

Figura 2 - Avaliação temporal do crescimento urbano. Base: Satélite Landsat 5 nas datas: 27/05/1975; 19/06/1986; 28/06/1995; 04/05/201

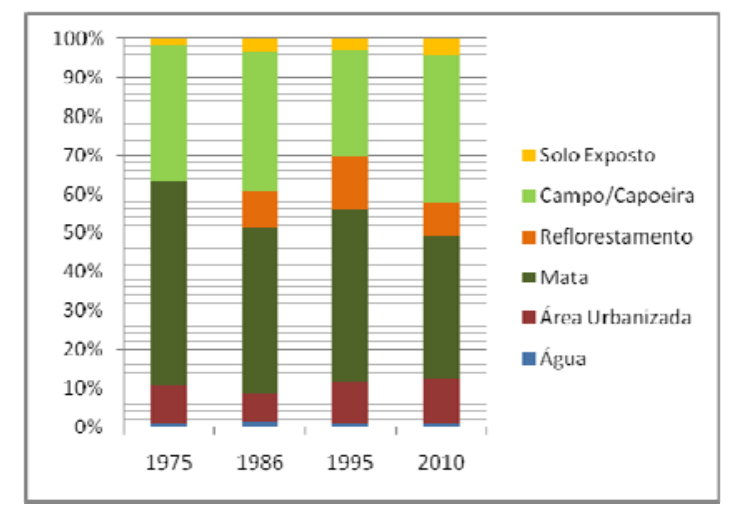

Gráfico 2 - Histograma da análise temporal das classes de uso do solo.

A Tabela 2 e Gráfico 3 contêm o porcentual relativo de crescimento e de regressão das áreas das classes de uso do solo estudadas (relacionado com o numero da área inicial de cada classe. Ou seja, representa o percentual de crescimento da área de cada classe de uso do solo relacionado com a área do período anterior. Como pode ser visualizado, um crescimento urbano como o que ocorreu entre 1986 e 1995 no valor de 2,9 pontos percentuais, conforme Tabela 1 representou um aumento de área urbanizada de 39\% em relação à data anterior (9 anos).

Como a imagem de 1975 possui menor resolução espacial se comparada às demais imagens, os AVALIAÇÃO TEMPORAL DO CRESCIMENTO DA... 
resultados apresentaram algumas incongruências, como a redução da área urbana entre os anos de 1975 e 1986, esse fenômeno não tem relação com a realidade mas pode ser explicado pela menor resolução espacial. Dessa forma, a avaliação numérica da supressão de matas só pôde ser feita para os anos de 1986, 1995 e 2010, identificandose, assim, que em 24 anos houve a perda da ordem de 7.000 hectares de matas, o que configura o desmatamento ocorrido na área. Se somarmos, em todas os quatro anos estudados, os valores das áreas de Mata e Reflorestamento conjuntamente, identificou-se que em 35 anos ocorreu a remoção de vegetação de porte arbóreo num total de 96,73 km ${ }^{2}$ - Entretanto, os reflorestamentos são áreas comerciais; portanto, um plantio realizado com o objetivo de produção é passível de corte. A soma da supressão da vegetação de porte arbóreo do reflorestamento com as matas é um dado que trata parcialmente do desmatamento ilegal.

A remoção de Pinus sp., por exemplo, muitas vezes, é fundamental para o desenvolvimento das matas, pois essa espécie atua como inibidora biológica e sua presença atrapalha bastante o crescimento de outras espécies arbóreas nativas. A remoção de Eucaliptus sp. tem também suas vantagens, pois supre a necessidade de madeira e serve como uma alternativa à proibição de corte de árvores nativas. Assim, não se pode chamar de desmatamento essas supressões, consideradas em conjunto nesta data avaliada (1975).

Tabela 2 - Variação histórica das classes do uso do solo.

\begin{tabular}{|c|c|c|c|c|c|c|c|}
\hline \multirow[b]{2}{*}{ CLASSE } & 1975 & & 1986 & \multicolumn{3}{|c|}{1995} & 2010 \\
\hline & Hectares & $\begin{array}{c}\text { IAR } \\
\%\end{array}$ & Hectares & $\begin{array}{c}\text { IAR } \\
\%\end{array}$ & Hectares & $\begin{array}{c}\text { IAR } \\
\%\end{array}$ & Hectares \\
\hline ÁGUA & $1.428,0$ & 21 & $1.731,9$ & -36 & $1.100,8$ & -24 & 833,6 \\
\hline ÁREA URBANA & $11.590,2$ & -22 & $9.083,1$ & 39 & $12.609,5$ & 15 & $14.527,1$ \\
\hline CAMPO/CAPOEIRA & $42.680,4$ & 2 & $43.538,6$ & -24 & $33.051,5$ & 41 & $46.674,1$ \\
\hline MATA & $64.234,8$ & -2 & $51.335,3^{*}$ & 6 & $54.476,1$ & -19 & $44.336,8$ \\
\hline REFLORESTAMENTO & & & $11.509,1$ & 45 & $16.743,3$ & -39 & $10.224,7$ \\
\hline S/DADO & & & 208,0 & & & & 2,3 \\
\hline SOLO EXPOSTO & $1.697,5$ & 149 & $4.225,0$ & -14 & $3.649,8$ & 38 & $5.032,2$ \\
\hline & IAR - Índ & de Alt & ção Rela & data & hterior & & \\
\hline
\end{tabular}

* os valores das áreas de mata e reflorestamento foram somados para calculo da alteração sofrida na data anterior.

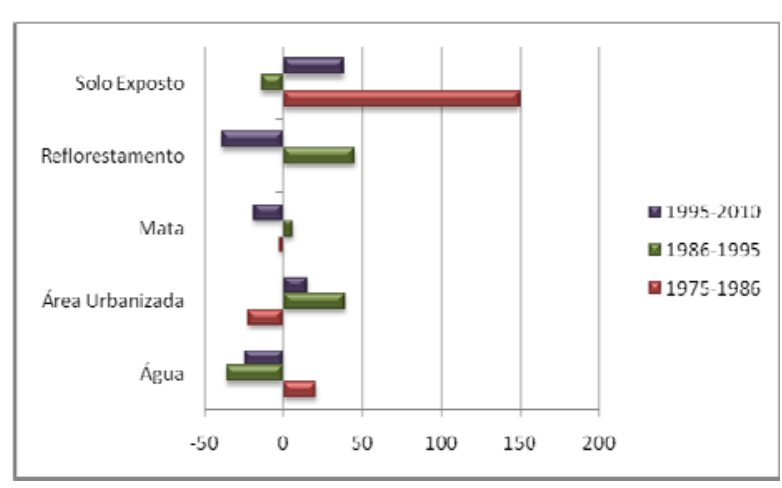

Gráfico 3 - Crescimento relativo em percentuais (\%) de cada classe de uso do solo.

De modo geral, com relação aos locais de supressão de vegetação arbórea dentro da área de estudo, observando as imagens, pode-se afirmar que ao longo do período analisado grande parte dos fragmentos com vegetação de porte arbóreo sofreu redução em suas áreas. A supressão florestal nesse Leite, J.R et al. 
período, de modo geral, foi difuso; os fragmentos foram sendo suprimidos pelas suas bordas, tornando suas áreas cada vez menores ao longo dos anos avaliados. Houve pontos que apresentaram uma maior concentração de supressão da vegetação, indicando que, em alguns trechos, foi mais intensa, dando em geral lugar a áreas urbanizadas. fragmentação são processos mais antigos nessa área em relação à parte sul. Nas partes central e sul do trecho estudado, identificou-se visualmente outros pontos de supressão mais concentrada, mas que se confundem muito com o processo de supressão difusa. Esses processos podem ser observados na figura 3.

Os dois maiores focos de supressão de vegetação estão localizados na parte norte do trecho estudado e indicam que o corte de árvores e aumento da

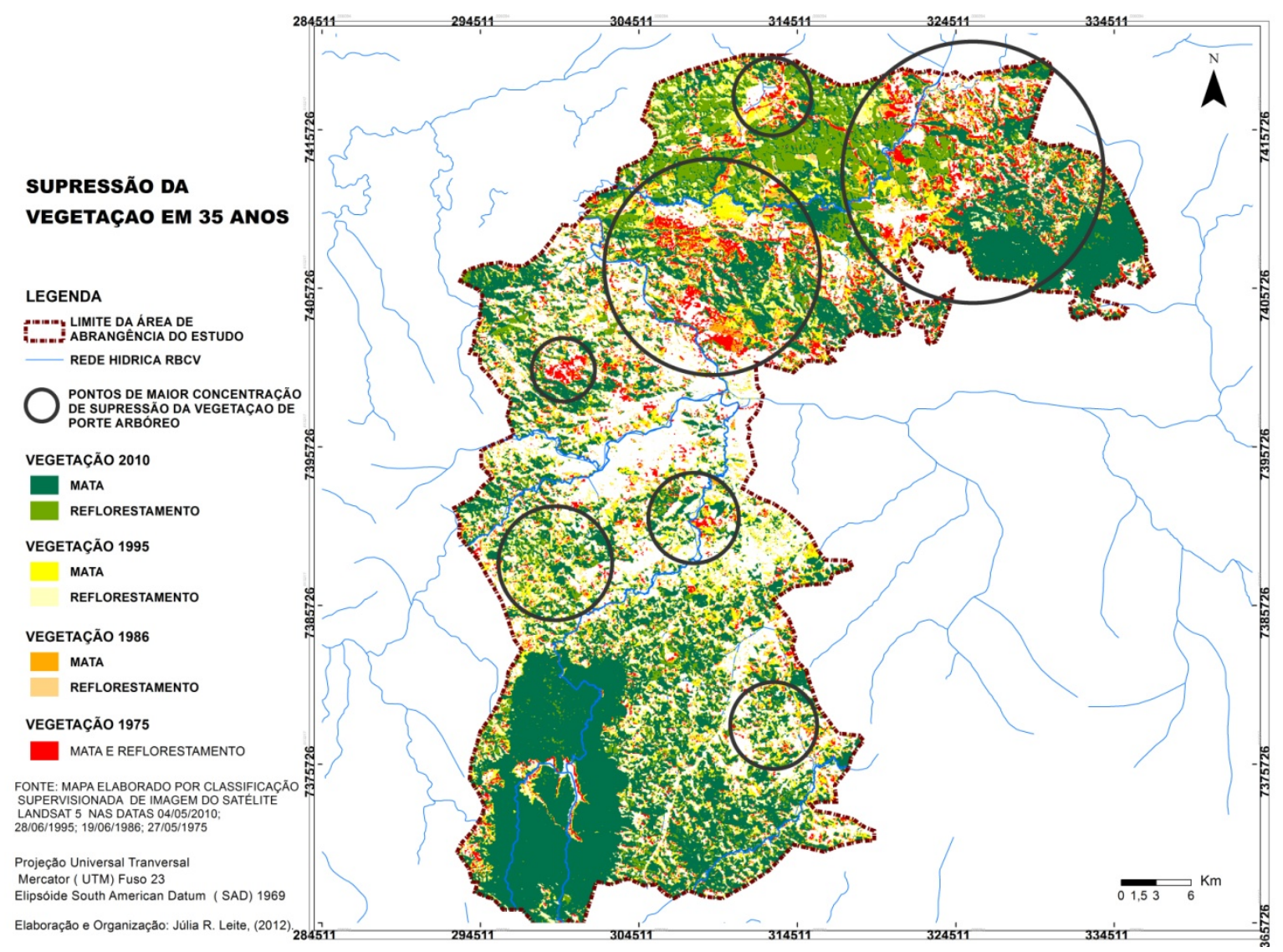

Figura 3 - Focos de maior supressão de vegetação na área estudada ao longo de 35 anos.

Entre 1986 e 1995, houve aumento de 6\% e 45\% das classes Matas e Reflorestamento, respectivamente, e a diminuição das áreas de Solo Exposto e Campo/Capoeira, em 14\% e 24\%, respectivamente. Isso pode ser explicado, mesmo que de modo especulativo, pela prática de reflorestamento com plantio de Eucalyptus sp. e Pinus sp., para silvicultura, que deve ter sido empreendida em terras anteriormente com Campo/Capoeira e Solo Exposto. Já o crescimento de Mata pode ter sido uma decorrência espontânea dos bosques de Reflorestamento compostos pó 
Eucalyptus sp., que, em alguns casos, conseguem estimular o crescimento de matas por funcionarem como vegetação pioneira e estimularem o crescimento e sucessão de sub-bosque vegetal ou de vegetação espontânea. Em um estudo fitossociologico de regeneração em áreas florestadas Nóbrega et al, (2008) puderam constatar que povoamento de Eucalyptus robusta com cerca de 20 anos de idade favoreceu a regeneração de espécies climácicas e secundárias. O aumento do índice de Matas ter ocorrido se desenvolveram sobre as áreas permeáveis, mas é importante frisar que, na década em questão, a prática recorrente de reflorestamento era o plantio das exóticas Eucalyptos sp e Pinus ( LEÃO, 2000).

Por outro lado, ainda analisando esse mesmo período, verifica-se um crescimento de áreas urbanizadas de 39\%, índice que corresponde a uma expansão urbana significativa em uma década.
Houve um crescimento das áreas urbanizadas de 54\% durante vinte e quatro anos, de caráter concentrado, quase que exclusivamente nas áreas marcadas na Figura 4. Isso ocorreu em função das facilidades e infraestruturas criadas pelas rodovias, pela linha de trem metropolitano da CPTM, por empreendimentos imobiliários, como condomínios e loteamentos de alto e médio padrão, e também alguns locais para habitações populares. O pólo mais significativo de crescimento urbano aconteceu entre os municípios de Barueri, Itapevi, Jandira e Santana do Parnaíba. Em Cotia e Carapicuíba, o crescimento urbano também se apresentou intensivo. Em todas as situações de adensamento, percebemos claramente uma ligação com as rodovias que funcionam como vetor de indução ao desenvolvimento dessas áreas.

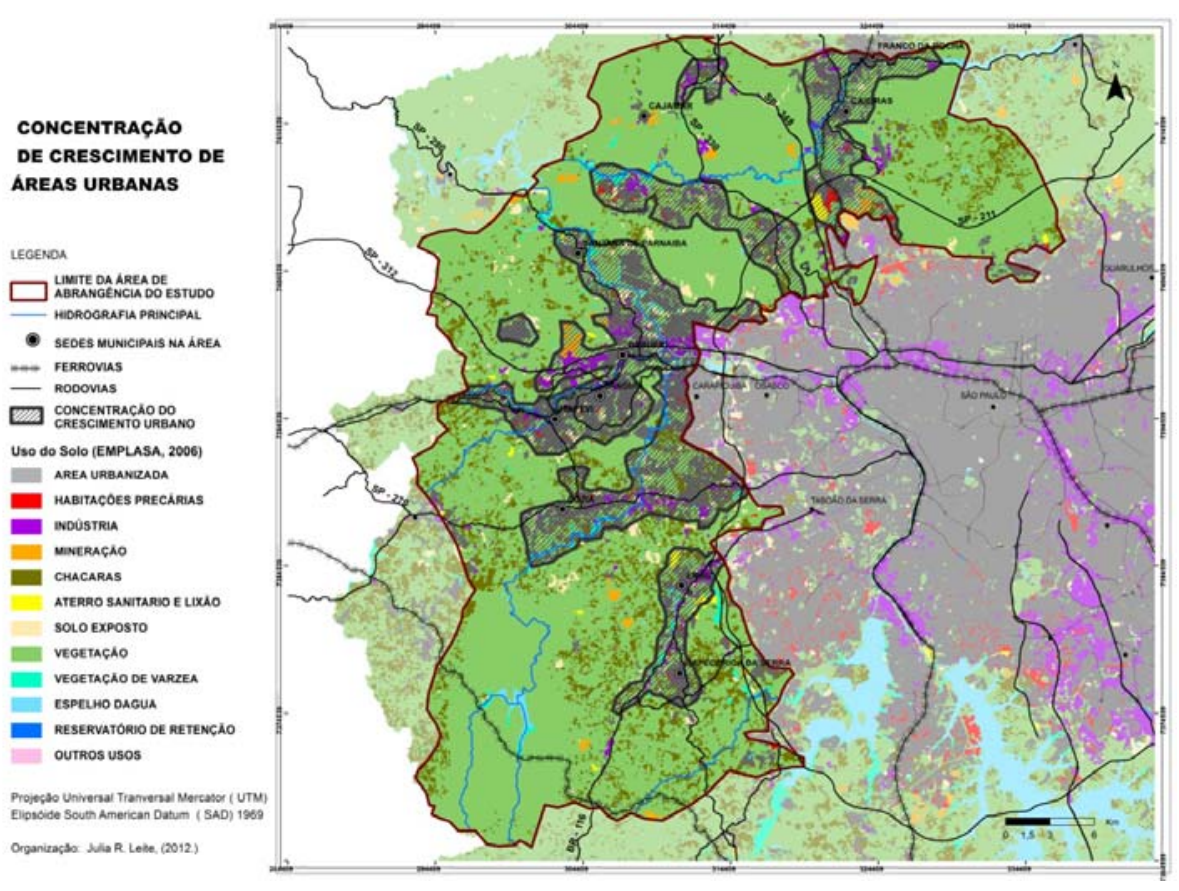

Figura 4 - Áreas onde houve uma maior concentração de crescimento urbano dentro do trecho estudado. 
Juntamente com os índices encontrados pode-se fazer uma interpretação da morfologia de crescimento urbano, a partir da área central da RMSP. Este crescimento se caracteriza por assumir uma forma radial, seguindo os eixos das principais rodovias que se originam na Capital, conferindo consequentemente, um formato linear aos espaços intersticiais ainda não ocupados pela urbanização, o que sugere faixas para o estudo de corredores secundários, que podem se originar do corredor perimetral principal, permeando as áreas já ocupadas, em direção ao Centro da Metrópole.

Neste sentido, estes avanços do Corredor Principal permitiriam uma conformação em rede dos corredores, ampliando as suas possibilidades de conexões e de propagação de seus impactos até áreas mais centrais da Metrópole, permitindo que possamos visualizar uma possível integração desta rede de corredores externos à mancha urbana, com o sistema de espaços abertos intraurbanos, e desta forma multiplicando as possibilidades de regeneração ecossistêmica mais sustentável das manchas que se encontram já totalmente isoladas dentro do tecido urbano, e, em sentido inverso, podendo também proporcionar uma imensa gama de usos de recreação, lazer e mobilidade dos usuários destes espaços para além de seus atuais confinamentos.

\section{CONCLUSOES}

A área estudada apresentou um índice de crescimento urbano constante ao logo do período estudado, indicando que as áreas que hoje não estão ocupadas e não correspondem a Unidades de Conservação Integral encontram-se ameaçadas diante de futuros empreendimentos que possam vir a ser feitos no trecho.

As informações a respeito da dinâmica temporal da paisagem estudada foram importantes pois indicaram na paisagem estudada os pontos em que os vetores de crescimento vêm causando transformações e impactos mais significativos em seus elementos naturais. Ou seja, serviu como uma base para a estratégia de desenhar um contínuo de elementos naturais, o qual deve, portanto, lidar com situações de barreiras aos fluxos ecológicos, que são resultantes dos processos de crescimento urbano, da presença de rodovias e estradas e da supressão da vegetação, elemento natural cuja existência é de fundamental importância, tanto para a manutenção da biodiversidade da área, como dos recursos hídricos e para a qualidade de vida da população. Não é apenas a vegetação arbórea, mas todas as áreas seminaturais, como os campos e solo exposto, os trechos de natureza mais ou menos intocada presentes, que possuem a potencialidade estratégica para recuperação e criação de paisagens que combinem uma conservação ecológica/ambiental com os usos urbanos.

Estes possíveis avanços em relação à uma estruturação mais pervasiva e funcional da Reserva da Biosfera do Cinturão Verde da RMSP permite uma continuidade de fornecimento dos serviços ecossistêmicos e econômicos que estes espaços resguardam. Isto pode tornar ainda mais defensável a conservação e implementação desses corredores, já que poderão também vir a desempenhar uma função determinante para uma estruturação urbana mais racional e sustentável, interagindo de forma ativa com o tecido urbano com o qual pode se AVALIAÇÃO TEMPORAL DO CRESCIMENTO DA... 
integrar e complementar, e, finalmente, permitir que a RBCV seja como um elemento fundamental para o crescimento sócio-econômico da metrópole à longo-prazo, além de garantir um bem-estar excepcional aos seus cidadãos, para que consigam desenvolver suas atividades mais plenamente e de forma mais gratificante, e não como uma camisa de força que impeça o crescimento da Cidade, como o nome da Reserva do cinturão verde pode sugerir.

\section{AGRADECIMENTOS}

À FAPESP - Fundação de Amparo à Pesquisa

Cientifica do Estado de São Paulo pelo apoio

financeiro e institucional (Processo $n^{0}$. 07/57736-8).

\section{BIBLIOGRAFIA}

AHERN, J. Planning for an extensive open space system: linking landscape structure an function in Landscape and Urban Planning, 1991. vol. 21, p. 131-145. Elsevier Science Publishers B. V. , Amsterdan.

D’ÁLGE, J.C.L. Cartografia para Geoprocessamento. In: Câmara, G.; Davis, C.; Monteira, A.M.V. Introdução a Ciência da Geoinformação. São José dos Campos: INPE, 2001. Livro Disponível em: < http://mtc-

m12.sid.inpe.br/col/sid.inpe.br/sergio/2004/04.22.07.43/doc/publicacao.pdf> acesso em 10/05/2011

EMPLASA, Empresa Paulista de Planejamento Metropolitano. Base Cartográfica do Uso do Solo e Temática da Região Metropolitana de São Paulo, São Paulo: 2006.

FAHRIG, L., Effects of habitat fragmentation on biodiversity. In Annual Review of Ecology, Evolution and Systematic, 2003. vol. 34, 487-515.

FORMAN, R. T. T.; ZONNEVELD, I. S.. Changing landscapes: An ecological perspective. New York: Springler-Verlag, 1990. 80p.

FORMAN, R. T. T.. Land Mosaics: The Ecology of Landscapes and Regions. Cambridge: Cambridge University Press, 1995. 632p.

GRONDONA, A. E. B., Avaliação da acurácia dos classificadores de máxima verossimilhança, mínima distância euclidiana e isodata na classificação de imagens da região do Pantanal. In. Anais do $2^{\circ}$ Simpósio de Geotecnologias do Pantanal, Corumbá, 7-11 novembro 2009, Embrapa Informática Agropecuária/INPE, p.433-442.

HELLMUND, P. H, Designing Greenways - Sustainable Landscapes for Nature and People. Washington D.C: Island Press, 2006. 270p. 
IBGE - Instituto Brasileiro de Geografia e Estatística. Mapa de vegetação do Brasil. 2. ed. Rio de Janeiro: 1993.

INPE, Instituto Nacional de Pesquisas Espaciais. Introdução ao Processamento de Imagens in Spring Manuais. São José dos Campos. s.d. disponível em:

<http://www.dpi.inpe.br/spring/portugues/tutorial/introducao_pro.html> acesso em 01/05/2011.

LEÃO, R.M. A Floresta e o homem. São Paulo: Editora da Universidade de São Paulo: Instituto de Pesquisa e Estudos Florestais, 2000. 434p.

LEITE, J.R., 2012. Corredores Ecológicos na Reserva da Biosfera do Cinturão Verde - Possibilidades e Conflitos. Tese de Doutorado, Faculdade de Arquitetura e Urbanismo, Área de Concentração: Paisagem e Ambiente, Universidade de São Paulo, São Paulo.

LINO, C. F.; DIAS, H.; ALBUQUERQUE, J. L. R.(org) Reserva da Biosfera da Mata Atlântica - Fase VI /2009 - Revisão e Atualização dos Limites e Zoneamento da Reserva da Biosfera da Mata Atlântica em Base Cartográfica Digitalizada . Série MaB - UNESCO, Caderno no. 38 . São Paulo: Conselho Nacional da Reserva da Biosfera da Mata Atlântica, 2009.

LUCHIARI, A. Identificação da cobertura vegetal em áreas urbanas por meio de produtos de sensoriamento remoto e de um sistema de informação geográfica. Revista do Departamento de Geografia (USP), São Paulo: 2001, n. 14, p. 47-58.

LUCHIARI, A. Os produtos do sensoriamento remoto nos mapeamentos do uso e cobertura da terra. In: José Borzacchiello da Silva, Denise Elias, Luiz Cruz Lima. (Org.). Panorama da Geografia Brasileira. 1 ed. São Paulo: Annablume, 2006, v. 2, p. 145-167.

MAGALHÃES, M. R. (coord. geral). Estrutura Ecológica da Paisagem: Conceitos e Delimitação, Escala Regional e Local. Lisboa: ISAPress, 2007. 368p.

METZGER, J. P. W. Estrutura da Paisagem e Fragmentação: Análise Bibliográfica. In An . Acad. Bras. Ci, 1999. vol. 71 , p. $441-462$

MEYER, R. M. P; GROINSTEIN, M.D. São Paulo Metrópole. São Paulo: Editora da Universidade de São Paulo: Imprensa Oficial do Estado de São Paulo, 2004. 289p.

MIRANDA, M. J. de ET AL. Clima dos Municípios Paulistas, a classificação climática de Koeppen para o estado de São Paulo. CEPAGRI-UNICAMP, S/d disponível em: <http://www.cpa.unicamp.br/outrasinformacoes/clima-dos-municipios-paulistas.html> acesso em 30/07/2012. 
MOREIRA, M. A. Informações uteis para auxiliar a interpretação visual de imagens de satélites. Inpe, s/d disponível em: <http://mtc m16.sid.inpe.br/col/sid.inpe.br/marciana/2005/01.06.13.32.23/doc/cap14.pdf> acesso em $25 / 04 / 2011$

NOBREGA, A.M. F. da; VALERI, S. V.; PAULA, R. C. de and SILVA, S. A. da. Regeneração natural em remanescentes florestais e áreas reflorestadas da várzea do rio Mogi-Guaçu, Luiz Antônio - SP. Rev.

Árvore [online]. 2008, vol.32, n.5, pp. 909-920. ISSN 0100-6762. http://dx.doi.org/10.1590/S010067622008000500016 .

NOVACK T. ; KARAM, H. A. ; LUCHIARI, A. ; CLARO, M. S. ; PEREIRA FILHO, A. J. Mapeamento automático de padrões de urbanização e cobertura da terra na Região metropolitana de São Paulo utilizando imagens CCD-CBERS-2. In: XIII Simpósio Brasileiro de Sensoriamento Remoto, 2007, Florianópolis. XIII Simpósio Brasileiro de Sensoriamento Remoto. São José dos Campos : Instituto Nacional de Pesquisas Espaciais - INPE, 2007. v. 1. p. 1001-1008.

RAIMUNDO, S. A paisagem natural remanescente na Região Metropolitana de São Paulo. São Paulo em Perspectiva, São Paulo, Fundação Seade, v. 20, n. 2, p. 19-31, abr./jun. 2006. Disponível em: $<$ http://www.seade.gov.br>; <http://www.scielo.br>

RODRIGUES, E.A.; VICTOR, R.A.B.M.; PIRES, B.C.C. A Reserva da Biosfera do Cinturão Verde na cidade de São Paulo como marco para a gestão integrada da cidade, seus serviços ambientais e o bem estar humano. In São Paulo em Perspectiva, São Paulo, Fundação Seade, v. 20, n. 2, p. 71-89, abr./jun. 2006. Disponível em: <http://www.seade.gov.br>;<http://www.scielo.br>.

SOARES et al. Avaliação da viabilidade de classificação de imagens fusionadas pelo uso de método de análise estatística. In Anais XV Simpósio Brasileiro de Sensoriamento Remoto, Curitiba, PR: INPE, 2011, p.2636-2643.

VENTURIERI, A. Curso de introdução às técnicas de Sensoriamento Remoto, Belém, 2007. Disponível em: <http://www.ufpa.br/epdir/images/docs/paper6> acesso em 24/04/2011.

VELOSO, H.P. Manual técnico da vegetação brasileira. Rio de Janeiro: IBGE, 1992.

(Série Manuais técnicos em geociências, n. 1).

VELOSO, H.P.; RANGEL FILHO, A.L.; LIMA, J. Classificação da vegetação brasileira, adaptada a um sistema universal. Rio de Janeiro: IBGE/Departamento de Recursos Naturais e Estudos Ambientais, 1991. 124 $\mathrm{P}$ 